\title{
Expression of TPX2 in salivary gland carcinomas
}

\author{
HIDEO SHIGEISHI, KOUJI OHTA, MISATO HIRAOKA, SHINICHI FUJIMOTO, \\ MASAHIKO MINAMI, KOICHIRO HIGASHIKAWA and NOBUYUKI KAMATA
}

Department of Oral and Maxillofacial Surgery, Division of Cervico-Gnathostomatology, Graduate School of Biomedical Sciences, Hiroshima University, 1-2-3 Kasumi, Minami-ku, Hiroshima 734-8553, Japan

Received August 19, 2008; Accepted November 10, 2008

DOI: $10.3892 /$ or_00000227

\begin{abstract}
TPX2 is a microtubule-associated protein and is required for microtubule formation at kinetochores in mammalian cells. The purpose of this study was to clarify the expression of TPX2 mRNA and correlation between TPX2 and clinicopathological factors in salivary gland carcinomas. The expression of TPX2 mRNA was investigated in 20 human salivary gland carcinomas (8 mucoepidermoid carcinomas, 7 adenoid cystic carcinomas, 5 acinic cell carcinomas) and 6 normal submandibular glands using real-time quantitative reverse transcription-polymerase chain reaction (RT-PCR). The mean expression level of TPX2 mRNA was higher in mucoepidermoid carcinomas $(0.53 \pm 0.51)$ than in normal submandibular glands $(0.047 \pm 0.029)$; a significant association was found (Mann-Whitney $\mathrm{U}$ test, $\mathrm{P}=0.0067$ ). The mean expression levels of TPX2 were also higher in acinic cell carcinomas $(0.45 \pm 0.49)$ and adenoid cystic carcinomas $(0.28 \pm 0.22)$ than in normal submandibular glands. Statistical correlations were found (Mann-Whitney $\mathrm{U}$ test, $\mathrm{P}=0.028$ and $\mathrm{P}=0.003$, respectively). Correlation between expression of TPX2 and receptor for hyaluronan-mediated motility (RHAMM) was also investigated in this study. A significant association was found between the mRNA expression levels of TPX and RHAMM (Pearson's correlation coefficient by rank test, $\mathrm{P}=0.020)$. These results indicate that human $T P X 2 \mathrm{mRNA}$ is closely linked to increased or abnormal cell proliferation in malignant salivary gland tumors.
\end{abstract}

\section{Introduction}

Chromosomes are segregated by a complex microtubule-based structure during mitosis. TPX2 was identified as a microtubuleassociated protein that mediates the binding of the $\mathrm{COOH}$ terminal domain of Xenopus kinesin-like protein 2 (Xklp2) to

Correspondence to: Dr Hideo Shigeishi, Department of Oral and Maxillofacial Surgery, Division of Cervico-Gnathostomatology, Graduate School of Biomedical Sciences, Hiroshima University, 1-2-3 Kasumi, Minami-ku, Hiroshima 734-8553, Japan

E-mail: shige@hiroshima-u.ac.jp

Key words: TPX2, microtubule-associated protein, salivary gland carcinomas microtubules (1). TPX2 is a microtubule-associated protein and is required for microtubule formation at kinetochores in mammalian cells (2). TPX2 initiates spindle assembly by bundling the microtubules and by activating Aurora A kinase in a microtubule-dependent manner (3).

GTPase Ran has been shown to stimulate microtubule polymerization in Xenopus egg extracts (4). GTPase Ran plays an important role for the spindle formation during mitosis (5). TPX2 is required for the GTPase Ran-dependent assembly of microtubules in Xenopus and mammalian cells $(6,7)$.

Previously, Maxwell et al reported that TPX2 interacts with the receptor for hyaluronan-mediated motility (RHAMM) (8). RHAMM has been identified as a cell surface receptor for hyaluronan and microtubule-associated protein, which interacts with the actin cytoskeleton $(9,10)$. RHAMM localizes to the centrosome, maintaining the spindle integrity through the direct interaction with microtubules (3). The amino terminus of RHAMM directly interacts with microtubules, while the carboxy-terminus is essential for centrosomal localization (9-12). RHAMM is also involved in regulating extracellularregulated kinase (ERK) (13).

Overexpression of TPX2 induces monopolar spindle structures in Xenopus egg extracts (14). Overexpression of TPX2 has been reported in human lung cancer (15). However, no attempt has been made to investigate the expression of the TPX2 gene in human salivary gland carcinomas. In this study, we examined the expression of human TPX2 mRNA in salivary gland carcinomas to clarify the correlation between TPX2 gene and clinicopathological parameters. mRNA expression levels of RHAMM were also examined to clarify the correlation between TPX2 and RHAMM.

\section{Materials and methods}

Tissue samples. We examined 20 salivary gland carcinomas: 8 mucoepidermoid carcinomas, 5 acinic cell carcinomas and 7 adenoid cystic carcinomas. Tumors were classified according to the histological classification of salivary gland tumors by WHO (16). The clinical staging was determined according to the International Union Against Cancer TNM classification (17). Salivary gland carcinoma tissues and specimens of normal submandibular glands were obtained with informed consent and approval from the Institutional Review Board at Hiroshima University Hospital. For molecular analyses, tissue samples obtained at the time of surgery were frozen immediately in liquid nitrogen and stored at $-80^{\circ} \mathrm{C}$. 
RNA extraction and quantitative RT-PCR analysis. RNA was extracted with an RNeasy mini kit (Qiagen, Hilden, Germany). One microgram of total RNA was subjected to a reverse-transcriptase reaction using the cDNA synthesis kit (Toyobo, Tokyo, Japan). mRNA levels were quantified using a real-time fluorescence detection method $(18,19)$. Fluorescence was detected using the laser detector of the Fluorescent Quantitative Detection System (LineGene FQD-33A, Bio Flux, Tokyo, Japan) and detection was carried out by measuring the binding of a fluorescent dye, SYBR-Green I, to double-stranded DNA. PCR was run in microtubes at a volume of $20 \mu 1$. The reaction mixture contained $1.0 \mu \mathrm{g}$ of cDNA, $10 \mu \mathrm{l}$ of SYBR-Green PCR master mix (Toyobo, Osaka, Japan) and 10 pmol of each pair of oligonucleotide primers. The primer sequences were: TPX2; 5'-ACCTTGCCCTACTAAGATT-3' (sense), 5'-AATGTG GCACAGGTTGAGC-3' (antisense), RHAMM; 5'-TCA TCATTACAGGAAGAAGCG-3' (sense), 5'-CTGTTGCTT GAGTTGGTTCTG-3' (antisense) and G3PDH; 5'-ACC ACAGTCCATGCCATCAC-3' (sense), 5'-TCCACCACC CTGTGGCTGTA-3' (antisense). The PCR program was as follows: initial melting at $95^{\circ} \mathrm{C}$ for $30 \mathrm{sec}$ followed by 40 cycles at $95^{\circ} \mathrm{C}$ for $15 \mathrm{sec}, 60^{\circ} \mathrm{C}$ for $10 \mathrm{sec}$ and $72^{\circ} \mathrm{C}$ for $15 \mathrm{sec}$. The threshold cycle (CT) of each PCR product was defined as the cycle number at which the fluorescence signal passed the fixed threshold. Duplicate samples for each case were examined. The average CT was calculated for both TPX2 and $G 3 P D H$ and $\triangle \mathrm{CT}$ (Average $\mathrm{CT}_{\mathrm{TPX} 2}$ - Average $\mathrm{CT}_{\mathrm{G} 3 \mathrm{PDH}}$ ) was determined. The relative quantification of TPX2 mRNA was calculated as $2^{-\Delta c t}(20)$.

Immunohistochemistry. Immunohistochemical staining was performed by the immunoperoxidase technique following antigen retrieval with microwave treatment $(500 \mathrm{~W}, 10 \mathrm{~min})$ in citrate buffer $\mathrm{pH} 6.0$ (21). After peroxidase block by $3 \%$ $\mathrm{H}_{2} \mathrm{O}_{2}$-methanol for $10 \mathrm{~min}$, specimens were blocked with PBS containing 5\% normal horse serum (Vector Laboratories, Inc., Burlingame, CA). For the staining of TPX2, anti-TPX2 rabbit polyclonal antibody (Lifespan Biosciences, Seattle, WA) (diluted 1:200) was used. After $12 \mathrm{~h}$ incubation at room temperature with primary antibody, specimens were rinsed briefly with PBS and incubated with secondary antibody for $1 \mathrm{~h}$ at room temperature. Specimens were rinsed with PBS and incubated with DAB (Dako, Tokyo, Japan).

Statistical methods. The results of quantitative RT-PCR analysis were compared with the patients' clinicopathological information using the Mann-Whitney $U$ test and Pearson's correlation coefficient test. P-values of $<0.05$ were regarded as statistically significant.

\section{Results}

Salivary gland carcinomas showed high levels of TPX2 mRNA expression compared to normal submandibular glands. The expression levels of TPX2 mRNA were significantly higher in 20 salivary gland carcinomas $(0.42 \pm 0.44)$ than in 6 normal submandibular glands $(0.047 \pm 0.029)$. The mean expression level of TPX2 mRNA was higher in mucoepidermoid carcinomas $(0.53 \pm 0.51)$ than in normal submandibular glands

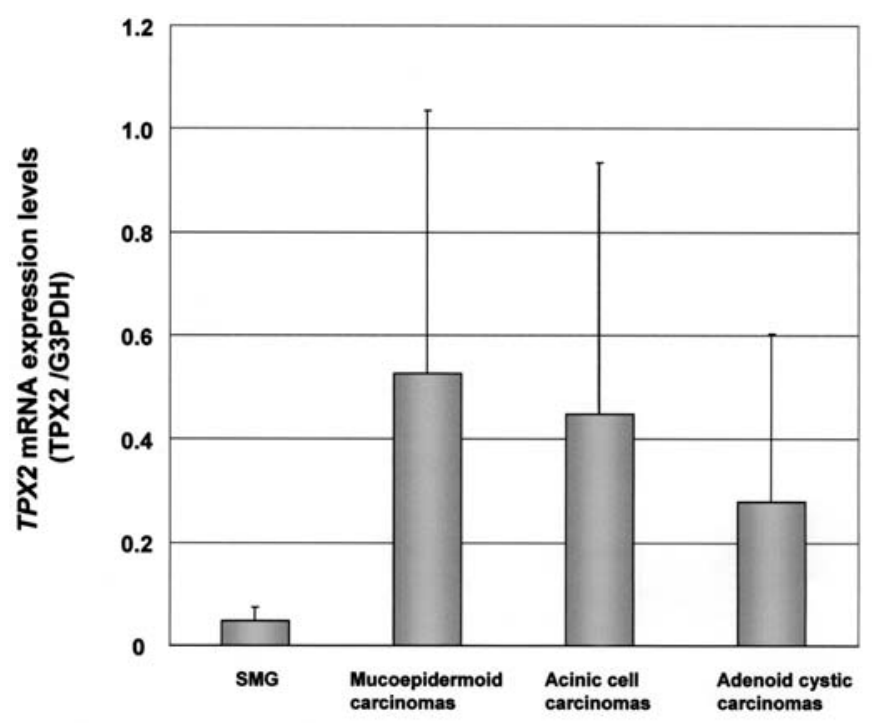

Figure 1. Levels of TPX2 mRNA expression in salivary gland carcinomas and normal submandibular glands by quantitative RT-PCR analysis. TPX2 mRNA expression levels were significantly higher in salivary gland carcinomas than submandibular glands.

Table I. Expression of TPX2 mRNA in salivary gland carcinomas and its correlation with clinicopathological parameters.

\begin{tabular}{lrlr}
\hline & & \multicolumn{2}{l}{ Expression level of TPX2 } \\
\cline { 3 - 4 } & Case no. & Mean \pm SD & P-value $^{\mathrm{b}}$ \\
\hline Tumor size & & & \\
T1/T2 & 14 & $0.35 \pm 0.43$ & 0.22 \\
T3/T4 & 6 & $0.58 \pm 0.43$ & \\
Clinical stage & & & 0.076 \\
I/II & 12 & $0.35 \pm 0.46$ & \\
III/IV & 8 & $0.54 \pm 0.39$ & \\
$\begin{array}{l}\text { Lymph node } \\
\text { metastasis }\end{array}$ & & & 0.32 \\
$\quad \begin{array}{l}\text { Negative } \\
\text { Positive }\end{array}$ & 15 & $0.40 \pm 0.45$ & \\
\hline
\end{tabular}

${ }^{a}$ According to the American Joint Committee on Cancer Staging

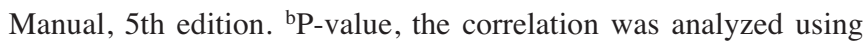
the Mann-Whitney U test and P-values are shown. P-values $<0.05$ were regarded as statistically significant.

as shown in Fig. 1. A significant association was found (Mann-Whitney U test, $\mathrm{P}=0.0067$ ). The mean expression levels of TPX2 were also higher in acinic cell carcinomas $(0.45 \pm 0.49)$ and adenoid cystic carcinomas $(0.28 \pm 0.32)$ than in normal submandibular glands. Statistical correlations were found (Mann-Whitney U test, $\mathrm{P}=0.028$ and $\mathrm{P}=0.003$, respectively). Data on TPX2 mRNA expression, tumor size, clinical stage and lymph node metastasis are summarized in Table I. The expression levels of TPX2 mRNA were higher in stage III/IV than in stage I/II (Mann-Whitney U test, $\mathrm{P}=0.076$ ). However, no significant correlation was found between the level of 


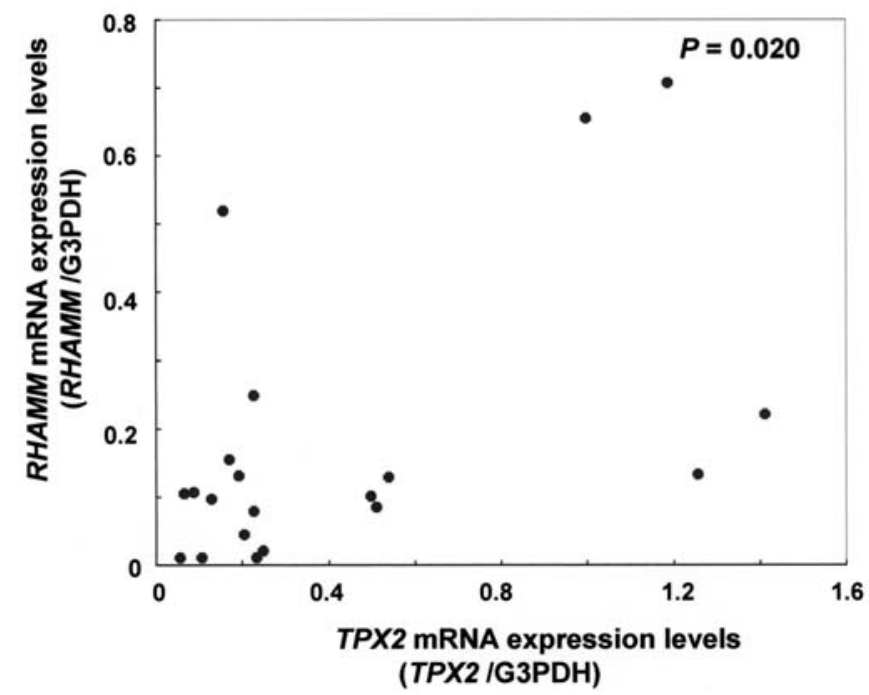

Figure 2. Correlation between mRNA expression levels of TPX2 and RHAMM (Pearson's correlation coefficient test, $\mathrm{P}=0.020$ )
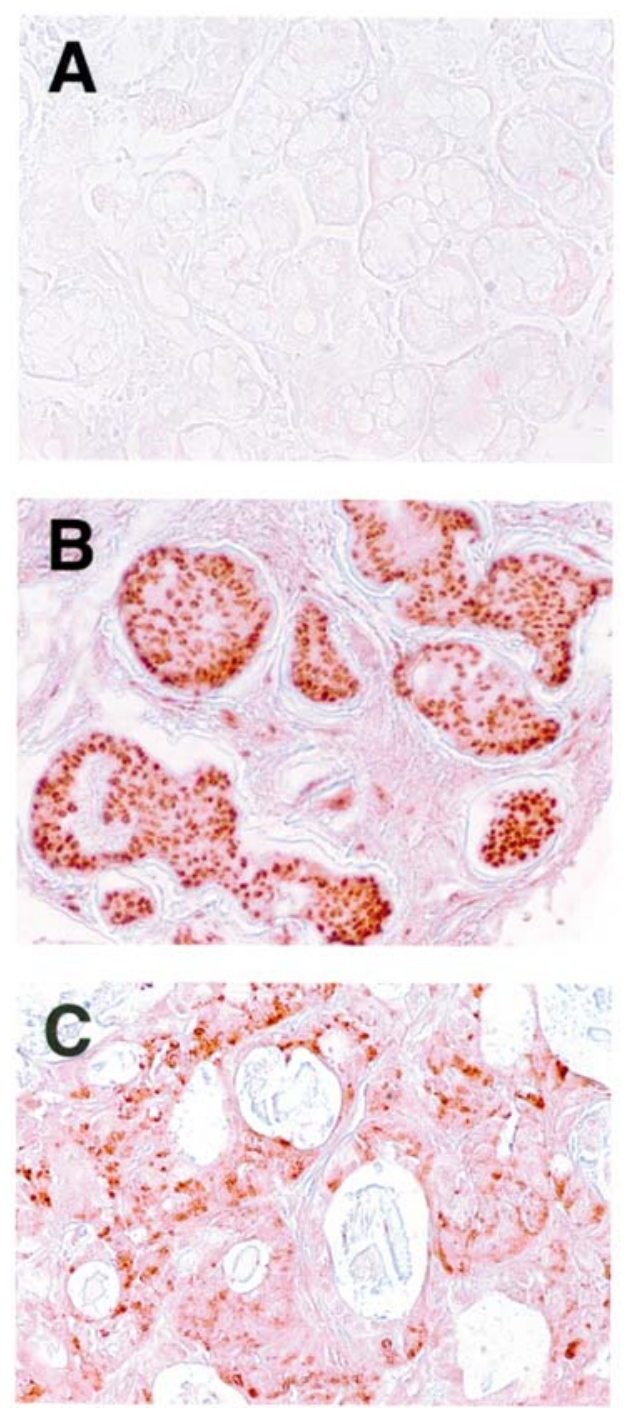

Figure 3. Immunohistochemistry for TPX2 in salivary gland carcinomas. (A) Normal submandibular glands showed weak or no immunoreactivity. (B) TPX2 expression was observed in the nucleus of the adenoid cystic carcinoma cells (tubular type). (C) TPX2 expression was observed in the nucleus of the mucoepidermoid carcinoma cells (low grade type).
TPX2 mRNA expression and tumor size/clinical stage. Next, expression levels of RHAMM mRNA were examined. The expression levels of RHAMM mRNA were higher in 20 salivary gland carcinomas $(0.42 \pm 0.44)$ than in normal submandibular glands $(0.047 \pm 0.029)$. A significant correlation was found between the mRNA expression levels of TPX and RHAMM (Pearson's correlation coefficient by rank test, $\mathrm{P}=0.020$ ) (Fig. 2).

To investigate the expression of TPX 2 protein, we performed immunohistochemical staining of TPX2. Tumor cell nuclei stained brown above the background level, regardless of intensity, were considered positively stained. TPX2 staining was graded as positive (at least $10 \%$ of tumor cells showed immunoreactivity) or negative $(<10 \%$ of tumor cells showed weak or no immunoreactivity). Normal submandibular glands showed weak or no immunoreactivity (Fig. 3A). Four of $8(50 \%)$ mucoepidermoid carcinomas, 2 of $5(40 \%)$ acinic cell carcinomas and 3 of $7(43 \%)$ adenoid cystic carcinomas showed positive expression of TPX2. Many of the tumor cells showed TPX2 positive expression in adenoid cystic carcinoma and mucoepidermoid carcinomas cases, as shown in Fig. 3B and C.

\section{Discussion}

Salivary gland carcinomas are uncommon and composed of histopathologically and clinically diverse entities. Salivary gland carcinomas showed several variations even in the same histological type. Mucoepidermoid carcinoma shows a widely diverse biological behavior. High-grade mucoepidermoid carcinoma is a highly aggressive tumor while low-grade shows a more benign nature $(1,22)$. Adenoid cystic carcinoma may show different histological patterns: cribriform, tubular and solid patterns (23). The characteristic biological features of the adenoid cystic carcinomas are local recurrences, perineural spread and late distant metastases. Despite understanding the clinical and biological behavior of malignant salivary gland tumors, the genetic mechanism of pathogenesis of each subtype are not well understood. In this study, we examined the expression of TPX2 mRNA in salivary gland carcinomas. Each type of carcinoma showed high levels of TPX2 mRNA expression compared to normal submandibular glands. Since the numbers of each salivary gland carcinoma cases investigated in this study were relatively small, the correlation of clinicopathological factors and expression levels of TPX2 mRNA in each type of carcinomas could not be clarified.

TPX2 has been identified as a microtubule-associated protein that accumulates in the nucleus during mitosis (7). Aurora A kinase accumulates at centrosomes from $\mathrm{S}$ phase to the end of mitosis and has been implicated in centrosome maturation and spindle assembly (3). Expression of Aurora A is associated with genetic instability and poor prognosis in human cancers (24). A direct interaction of TPX2 with Aurora A kinase has been reported and seemed to be required for targeting of the kinase to spindle microtubules (25). TPX2 plays an important role in microtubule formation at kinetochores and is essential for mitosis in mammalian cells. Recently, overexpression of TPX2 has been reported in human squamous cell carcinomas of the lung. We have also identified increased expression levels of TPX2 mRNA in human oral 
squamous cell carcinomas (unpublished data). Overexpression of TPX2 might contribute to the abnormal cell cycle condition in human cancer cells.

Furthermore, a correlation was found between the mRNA expression levels of TPX2 and RHAMM. The results indicate that RHAMM associates with centrosome abnormalities in human salivary gland carcinomas. Our observations suggest that the up-regulations of human TPX2 and RHAMM correlate with the malignant condition of salivary gland carcinomas. In conclusion, increased expression of TPX2 might play an important role in the loss of cell cycle inhibition and proliferation of salivary gland carcinomas.

\section{Acknowledgements}

This study was supported by a Grant-in-aid (No. 17791461) from the Japanese Ministry of Education, Culture, Sports and Technology.

\section{References}

1. Wittmann T, Boleti H, Antony C, Karsenti E and Vernos I: Localization of the kinesin-like protein Xklp2 to spindle poles requires a leucine zipper, a microtubule-associated protein, and dynein. J Cell Biol 143: 673-685, 1999.

2. Tulu US, Fagerstrom C, Ferenz NP and Wadsworth P: Molecular requirements for kinetochore-associated microtubule formation in mammalian cells. Curr Biol 16: 536-541, 2006.

3. Tsai MY, Wiese C, Cao K, Martin O, Donovan P, Ruderman J, Prigent $C$ and Zheng Y: A Ran signalling pathway mediated by the mitotic kinase Aurora A in spindle assembly. Nat Cell Biol 5: 242-248, 2003

4. Zhang C, Hughes $M$ and Clarke PR: Ran-GTP stabilises microtubule asters and inhibits nuclear assembly in Xenopus egg extracts. J Cell Sci 112: 2453-2461, 1999.

5. Guarguaglini G, Renzi L, D'Ottavio F, Di Fiore B, Casenghi M and Cundari E: Regulated Ran-binding protein 1 activity is required for organization and function of the mitotic spindle in mammalian cells in vivo. Cell Growth Differ 11: 455-465, 2000.

6. Gruss OJ, Carazo-Salas RE, Schatz CA, Guarguaglini G, Kast J and Wilm M: Ran induces spindle assembly by reversing the inhibitory effect of importin alpha on TPX2 activity. Cell 104: 83-93, 2001.

7. Gruss OJ, Wittmann M, Yokoyama H, Pepperkok R, Kufer T and Silljé H: Chromosome-induced microtubule assembly mediated by TPX2 is required for spindle formation in HeLa cells. Nat Cell Biol 4: 871-879, 2002

8. Maxwell CA, Keats JJ, Belch AR, Pilarski LM and Reiman T: Receptor for hyaluronan-mediated motility correlates with centrosome abnormalities in multiple myeloma and maintains mitotic integrity. Cancer Res 65: 850-860, 2005.
9. Hardwick C, Hoare K, Owens R, Hohn HP, Hook M and Moore D: Molecular cloning of a novel hyaluronan receptor that mediates tumor cell motility. J Cell Biol 117: 1343-1350, 1992.

10. Assmann V, Jenkinson D, Marshall JF and Hart IR: The intracellular hyaluronan receptor RHAMM/IHABP interacts with microtubules and actin filaments. J Cell Sci 112: 3943-3954, 1999.

11. Maxwell CA, Keats JJ, Crainie M, Sun X, Yen T and Shibuya E: RHAMM is a centrosomal protein that interacts with dynein and maintains spindle pole stability. Mol Biol Cell 14: 2262-2276, 2003.

12. Zhang S, Chang MC, Zylka D, Turley S, Harrison R and Turley EA: The hyaluronan receptor RHAMM regulates extracellular-regulated kinase. J Biol Chem 273: 11342-11348, 1998.

13. Rudolph P, Alm P, Heidebrecht HJ, Bolte H, Ratjen V and Baldetorp B: Immunologic proliferation marker Ki-S2 as prognostic indicator for lymph node-negative breast cancer. J Natl Cancer Inst 91: 271-278, 1999.

14. Wittmann T, Wilm M, Karsenti E and Vernos I: TPX2, A novel xenopus MAP involved in spindle pole organization. J Cell Biol 149: 1405-1418, 2000.

15. Ma Y, Lin D, Sun W, Xiao T, Yuan J and Han N: Expression of targeting protein for xklp2 associated with both malignant transformation of respiratory epithelium and progression of squamous cell lung cancer. Clin Cancer Res 12: 1121-1127, 2006.

16. World Health Organization Classification of Tumors. Pathology and genetics. Head and Neck Tumors, 2005.

17. Ellis GL and Auclair PL: Tumors of the salivary glands. In: Atlas of Tumor Pathology. Rosai J, Sobin LH (eds). Armed Forces Institute of Pathology, Washington DC, 1995.

18. Simpson D, Feeney S, Boyle C and Stitt AW: Retinal VEGF mRNA measured by SYBR green I fluorescence: A versatile approach to quantitative PCR. Mol Vis 5: 178-183, 2000.

19. Kubista M, Andrade JM, Bengtsson M, Forootan A, Jonák J and Lind K: The real-time polymerase chain reaction. Mol Aspects Med 27: 95-125, 2006.

20. Livak KJ and Schmittgen TD: Analysis of relative gene expression data using real-time quantitative PCR and the 2(-Delta Delta C(T)) method. Methods 25: 402-408, 2001.

21. Kuniyasu H, Oue N, Shigeishi H, Ito R, Kato Y, Yokozaki H and Yasui W: Prospective study of Ki-67 labeling index in the mucosa adjacent to cancer as a marker for colorectal cancer metastasis. J Exp Clin Cancer Res 20: 543-548, 2001.

22. Guzzo M, Andreola S, Sirizzotti G and Cantu G: Mucoepidermoid carcinoma of the salivary glands: clinicopathologic review of 108 patients treated at the National Cancer Institute of Milan. Ann Surg Oncol 9: 688-695, 2002.

23. Matsuba HM, Spector GJ, Thawley SE, Simpson JR, Mauney M and Pikul FJ: Adenoid cystic salivary gland carcinoma. A histopathologic review of treatment failure patterns. Cancer 57: 519-524, 1986.

24. Fu J, Bian M, Jiang Q and Zhang C: Roles of Aurora kinases in mitosis and tumorigenesis. Mol Cancer Res 5: 1-10, 2007.

25. Kufer TA, Silljé HH, Körner R, Gruss OJ, Meraldi P and Nigg EA: Human TPX2 is required for targeting Aurora-A kinase to the spindle. J Cell Biol 158: 617-623, 2002. 